\title{
Survey response burden in caregivers of civilians and service members/veterans with traumatic brain injury
}

This article was published in the following Dove Press journal: Patient Related Outcome Measures

\author{
Elizabeth A Hahn ${ }^{1,2}$ \\ Phillip A lanni ${ }^{3}$ \\ Robin A Hanks ${ }^{4}$ \\ Jennifer A Miner ${ }^{3}$ \\ Jenna Freedman ${ }^{3}$ \\ Noelle E Carlozzi ${ }^{3}$ \\ 'Department of Medical Social \\ Sciences, Northwestern University \\ Feinberg School of Medicine, Chicago, \\ IL, USA; ${ }^{2}$ Center for Patient-Centered \\ Outcomes, Northwestern University \\ Feinberg School of Medicine, \\ Chicago, IL, USA; ${ }^{3}$ Center for \\ Clinical Outcomes Development and \\ Application (CODA), Department of \\ Physical Medicine and Rehabilitation, \\ University of Michigan, Ann Arbor, \\ MI, USA; ${ }^{4}$ Department of Physical \\ Medicine and Rehabilitation, School \\ of Medicine, Wayne State University, \\ Detroit, MI, USA
} demands and/or stress associated with caregiving. using the computer or answering the questions.
Purpose: Caregivers have expressed interest in survey research, yet there is limited information available about survey response burden, ie, the time, effort, and other demands needed to complete the survey. This may be particularly important for caregivers due to excessive time

Method: Survey response burden indicators were collected as part of a study to develop and validate a patient-reported outcome (PRO) measurement system for caregivers of civilians or service members/veterans (SMVs) with traumatic brain injury (TBI).

Results: Compared to the group caring for civilians ( $n=335)$, the group caring for SMVs $(n=123)$ was comprised of all women, was younger, had fewer racial/ethnic minorities, had more education, and nearly all were the spouse of a person with TBI. All PRO outcomes were poorer for the group caring for SMVs. Although the caregivers of SMVs had poorer PRO outcomes compared to caregivers of civilians, they were more likely to report that they would recommend the study to others. Caregivers with less education and those from racial/ethnic minority groups had more favorable ratings of their study participation experience, even though they needed more help

Conclusion: The results of this study provide useful information about the acceptability of computer-based survey administration for caregiver PROs. PROs are widely gathered in clinical and health services research and could be particularly useful in TBI care programs. More data are needed to determine the best assessment strategies for individuals with lower education who are likely to require some assistance completing PRO surveys. Studies evaluating PROs administered by multimedia platforms could help researchers and clinicians plan the best strategies for assessing health-related quality of life in TBI caregivers.

Keywords: patient-reported outcomes, computer-based survey administration, study participation ratings, military personnel

\section{Introduction}

Caregivers of people with moderate to severe traumatic brain injury (TBI) are at risk for poor health-related quality life (HRQOL) ${ }^{1-7}$ Caregivers of service members or veterans (SMVs) with TBI face unique challenges navigating the military health care system, and may experience even greater burden and worse HRQOL than caregivers of civilians with TBI. ${ }^{5,8-13}$ Assessing HRQOL in caregivers of individuals with TBI is complicated by the lack of a gold standard assessment tool specific to this population. To address this need, the TBI-CareQOL study developed a patient-reported outcome (PRO) measurement system that captures both the generic and unique aspects of HRQOL significant to caregivers of civilians or SMVs with TBI. ${ }^{4,5,14}$ Briefly, TBI-CareQOL
Correspondence: Elizabeth A Hahn Department of Medical Social Sciences, Northwestern University Feinberg School of Medicine, 633 N. Saint Clair Street, Suite 1900, Chicago, IL 606II, USA

Tel +I 3125039804

Email e-hahn@northwestern.edu 
measurement development involved qualitative methods to identify relevant aspects of HRQOL for both caregivers of civilians and SMVs. Areas requiring new development included several iterations of item development and review. Quantitative field testing of items was conducted, and detailed analyses included both classical test theory approaches and item response theory analytical approaches for final item selection. The study utilized modern psychometric and health information technology methods from PROMIS (PatientReported Outcomes Measurement Information System). ${ }^{15}$

Health information technology advances have increased the number of available PRO survey administration options. However, different methods of administration require different skills and resources of people being asked to complete the survey; this means that the choice of method of administration may result in differing levels of respondent burden. ${ }^{16}$ One important methodological standard for a PRO instrument is to minimize respondent burden, ie, the time, effort, and other demands needed to complete the instrument. ${ }^{17-21}$ This may be particularly important for caregivers due to excessive time demands and/or stress associated with caregiving. ${ }^{22-24}$ Caregivers have expressed interest in survey research, $, 4,25$ yet there is limited information available about respondent burden. ${ }^{26}$ In addition to addressing item wording, literacy level, questionnaire length, and questionnaire formatting during instrument development, it is useful to obtain respondent feedback after completion of the questionnaire. ${ }^{19,27-29}$

As part of the TBI-CareQOL study to develop and validate a PRO measurement system for TBI caregivers, respondents were asked to complete a short evaluation survey at the end of the online assessment. The purpose of this paper is to present the results of this evaluation survey, which included indicators of response burden. It was hypothesized that caregivers with less education would report more burden completing online computer surveys compared to those with more education. There were no specific hypotheses about response burden for caregivers of civilians vs SMVs or for racial/ethnic minorities, although there was interest in evaluating burden across these subgroups.

\section{Methods}

\section{Participants}

Caregivers of civilians with TBI were recruited from the Kessler Foundation, the Rehabilitation Institute of Michigan (RIM), The Institute for Rehabilitation and Research (TIRR) Memorial Hermann Rehabilitation Hospital, and the University of Michigan Medical School. Caregivers of SMVs with TBI were recruited primarily through military caregiver support organizations, eg, Hearts of Valor. Multiple recruitment strategies for convenience sampling were implemented, including existing TBI caregiver databases, medical record data capture systems, ${ }^{30}$ and hospital-based and community outreach efforts. For both groups, caregivers were at least 18 years old, English-speaking, and were caring for an individual who sustained a medically documented TBI after age of 16 years. The individual with the TBI had to be at least 1 year post-injury. The TIRR Institutional Review Board (IRB) approved a waiver of consent because this research was considered to be of low risk. The Kessler Foundation IRB, RIM: Wayne State University IRB, and the University of Michigan Medical School IRB approved both a waiver of written informed consent (to allow for telephone consent) as well as in-person written consent. Each participant received US\$50 for completing the study.

\section{Measures and method of administration}

Sociodemographic data were obtained by self-report on the survey, and information about the person with TBI was obtained by medical record review or by caregiver report. The Mayo-Portland Adaptability Inventory-Fourth Edition $(\text { MPAI-4) })^{31}$ was completed by caregivers as a measure of the functional ability of the person with TBI. MPAI-4 items represent the range of physical, cognitive, emotional, behavioral, and social problems that people may encounter after an acquired brain injury. MPAI-4 scores were dichotomized to indicate low functioning/more impairment (score $\geq 60$ ) vs high functioning/less impairment (score <60). ${ }^{32}$ Caregivers completed four TBI-CareQOL item pools; all items were written at approximately a fifth-grade reading level. The 66-item Caregiver Strain item pool captured feelings of being overwhelmed, stressed, self-defeated, downtrodden, and "beat-down" related to the caregiver role. The 81-item Caregiver-Specific Anxiety item pool captured feelings of worry and anxiety specific to general safety, health, and future well-being of the person with the injury. The 28-item Feeling Trapped item pool captured feelings of being unable to go places or do things due to caregiving responsibilities. The 98-item Feelings of Loss item pool captured feelings of loss for the caregivers themselves (including loss of self, relationships, activities, and future plans) and feelings of loss with regard to the person with TBI (including loss of abilities, loss of potential/failure, and changes in behavior/personality).

Participants next completed 10 measures from PROMIS ${ }^{15}$ which used approximately a sixth-grade reading level for most items. ${ }^{33}$ The PROMIS measures were Depression (feelings of sadness and worthlessness), Anxiety (fear, anxiety, and 
hyperarousal), Anger (irritability and frustration), Ability to Participate in Social Roles and Activities (involvement in one's usual social roles and activities), Satisfaction with Social Roles and Activities (satisfaction in one's usual social roles and activities), Emotional Support (feelings of being cared for and having supportive relationships), Informational Support (ability to access helpful information and advice), Social Isolation (feelings of being emotionally cut off from other people), Fatigue (feelings of tiredness and exhaustion related to being overwhelmed), and Sleep Disturbance (sleep quality, depth, and restorative sleep). All PROMIS measures were administered as computer-adaptive tests. Additional instruments were administered in this study, but were not included in this paper.

Participants were asked to complete PRO surveys through the PROMIS Assessment Center online platform (http:// www.assessmentcenter.net), either at a designated computer at the site or on their own computer. After all PROs were completed, a short five-item evaluation survey was presented: 1) "Compared to what you expected, how would you rate your experience participating in this research study?" (a lot worse than expected, a little worse than expected, about the same as expected, a little better than expected, a lot better than expected); 2) "Would you recommend this research study to other people?" (no, maybe, yes); 3) "Do you have any comments or suggestions?" (open-ended); 4) "What is your overall rating of the design of the screens, including the colors and the layout?" (poor, fair, good, very good, excellent); and 5) "Did you receive any help using the computer or answering any of the questions?" (not at all, a little bit, some, a lot). Since these five evaluation questions were presented at the end of the online assessment, they were not presented to participants who stopped before completing all of the PRO surveys. Two or three of the authors independently coded responses to the open-ended evaluation question; all three coders met to resolve all discrepancies. Participant responses were coded as positive, negative, psychological, or other. Responses were coded as "positive" if most of the content of the response indicated that the participant had a positive opinion of the study and/or questionnaires, eg, "I think I learned a lot about myself." Brief comments like "thank you" or "good luck" were also coded as "positive." Responses were coded as "negative" if most of the content of the response indicated that the participant had a negative opinion of the study and/or questionnaires, eg, "I think the survey was a little too long." Responses were coded as "psychological" if the participant "told a story" without content relevant to study burden, eg, "My daughter is in a nursing home and doesn't go out much." Responses were coded as "other" if they did not fit into the other categories, eg, "Make a mobile version." If a response included multiple themes, classification as positive or negative took precedence. The amount of time needed to complete the surveys was automatically recorded by the assessment platform.

\section{Statistical analysis}

Item response theory-based scores for all TBI-CareQOL and PROMIS measures were standardized using T-scores $(\mathrm{M}=50, \mathrm{SD}=10)^{15}$; higher scores indicate more of the trait being measured. Thus, for negative traits (Caregiver Strain, Caregiver-Specific Anxiety, Feeling Trapped, Feelings of Loss, Depression, Anxiety, Anger, Social Isolation, Fatigue, Sleep Disturbance), higher scores indicate worse HRQOL, whereas for positive traits (Ability to Participate in Social Roles and Activities, Satisfaction with Social Roles and Activities, Emotional Support, Informational Support) higher scores indicate better HRQOL.

The total time to complete the assessment was greater than 3 hours for $31 \%$ of the participants $(n=140)$. Since many of these participants had data that spanned across multiple days, it was assumed that these individuals took breaks; thus, they were excluded from analyses that examined number of minutes for completion. Chi-squared tests, Fisher's exact tests, and analysis of variance methods were used to compare the two caregiver groups on sociodemographic and clinical characteristics, PROs, and response burden indicators. Separate multivariable logistic regression models were estimated to evaluate the effects of caregiver group, education (more than high school vs less education), race/ethnicity (non-Hispanic white vs others), MPAI-4 (low vs high functioning), and PROs on study participation experience (a little/a lot better vs same/worse), study recommendation (yes vs no/maybe), and help completing the assessment (some/a little/a lot vs none). ORs and $95 \%$ CIs were estimated. A chi-squared test was used to evaluate the association between help provided in completing the assessment and evaluation comments (positive vs negative vs psychological/other). A nominal significance level of 0.05 was used to interpret the results.

\section{Results}

Of the 473 individuals who were enrolled in the TBICareQOL study, 458 participants (97\%) completed the evaluation questions at the end of the assessment and were included in the analyses; 335 were caregivers for civilians with TBI and 123 were caregivers for SMVs with TBI. The two groups were very different (Table 1). Compared to the group caring for civilians, the group caring for SMVs was 
Table I Sociodemographic and clinical characteristics, and health-related quality of life outcomes of study participants, by caregiver type

\begin{tabular}{|c|c|c|c|c|}
\hline $\begin{array}{l}\text { Sociodemographic and clinical } \\
\text { characteristics }\end{array}$ & $\begin{array}{l}\text { Caregivers of } \\
\text { civilian TBI } \\
(n=335)\end{array}$ & $\begin{array}{l}\text { Caregivers of } \\
\text { SMV TBI } \\
(n=\mid 23)\end{array}$ & $\begin{array}{l}\text { Total } \\
(n=458)\end{array}$ & $P$-value ${ }^{a}$ \\
\hline \multicolumn{5}{|l|}{ Caregiver } \\
\hline Female gender & $259(77 \%)$ & $123(100 \%)$ & $382(83 \%)$ & $<0.001$ \\
\hline Age (years) & $51.8(13.9)$ & $35.6(8.6)$ & $47.5(14.6)$ & $<0.001$ \\
\hline \multicolumn{5}{|l|}{ Ethnicity, race } \\
\hline Hispanic, any race & $36(11 \%)$ & $10(8 \%)$ & $48(10 \%)$ & $<0.001$ \\
\hline Non-Hispanic, white & $212(63 \%)$ & $88(72 \%)$ & $300(66 \%)$ & \\
\hline Non-Hispanic, black & $68(20 \%)$ & $6(5 \%)$ & $74(16 \%)$ & \\
\hline Other & $12(4 \%)$ & $13(11 \%)$ & $25(5 \%)$ & \\
\hline Missing & $5(1 \%)$ & $6(5 \%)$ & II (2\%) & \\
\hline \multicolumn{5}{|l|}{ Highest education } \\
\hline Less than HS & 45 (13\%) & $3(2 \%)$ & $48(10 \%)$ & $<0.001$ \\
\hline HS/GED & 45 (13\%) & $5(4 \%)$ & $50(11 \%)$ & \\
\hline More than HS & $245(73 \%)$ & 115 (94\%) & $360(79 \%)$ & \\
\hline \multicolumn{5}{|l|}{ Relationship to person with $\mathrm{TBI}$} \\
\hline Spouse & $123(37 \%)$ & $118(96 \%)$ & $24 \mid(53 \%)$ & $<0.001$ \\
\hline Parent & $121(36 \%)$ & $5(4 \%)$ & $126(28 \%)$ & \\
\hline Child/other family member & $64(19 \%)$ & 0 & $64(14 \%)$ & \\
\hline Other & $27(8 \%)$ & 0 & $27(6 \%)$ & \\
\hline Years in caregiver role & $6.0(6.5)$ & $5.6(2.9)$ & $5.9(5.7)$ & 0.410 \\
\hline \multicolumn{5}{|l|}{ Person with TBI } \\
\hline Female gender & 85 (25\%) & 0 & 85 (19\%) & $<0.001$ \\
\hline Age (years) & $42.4(14.7)$ & $36.1(7.3)$ & $40.7(13.4)$ & $<0.001$ \\
\hline Time since injury (years) & $6.9(5.5)$ & $8.6(4.7)$ & $7.4(5.4)$ & 0.003 \\
\hline \multicolumn{5}{|l|}{ Level of functioning (MPAI-4) } \\
\hline High functioning/low impairment & $293(87 \%)$ & 57 46\%) & $350(76 \%)$ & $<0.001$ \\
\hline Low functioning/high impairment & $42(13 \%)$ & $63(51 \%)$ & $105(23 \%)$ & \\
\hline Missing & 0 & $3(2 \%)$ & $3(1 \%)$ & \\
\hline \multicolumn{5}{|l|}{ Caregiver health-related quality of life } \\
\hline \multicolumn{5}{|l|}{ TBI-CareQOL } \\
\hline Caregiver strain & $47.5(9.8)$ & $55.2(7.5)$ & $49.6(9.8)$ & $<0.001$ \\
\hline Caregiver-specific anxiety & $47.1(9.3)$ & $56.8(8.0)$ & $49.8(9.9)$ & $<0.001$ \\
\hline Feeling trapped & $46.5(9.2)$ & $57.2(6.6)$ & $49.4(9.8)$ & $<0.001$ \\
\hline Feelings of loss-self & $48.2(9.8)$ & $55.4(7.5)$ & $50.2(9.8)$ & $<0.001$ \\
\hline Feelings of loss-person with TBI & $49.6(10.2)$ & $52.9(7.3)$ & $50.5(9.6)$ & $<0.001$ \\
\hline \multicolumn{5}{|l|}{ PROMIS } \\
\hline Anger & $51.2(9.8)$ & $59.2(9.4)$ & $53.4(10.3)$ & $<0.001$ \\
\hline Anxiety & $52.4(9.1)$ & $61.3(8.6)$ & $54.8(9.8)$ & $<0.001$ \\
\hline Depression & $50.2(9.6)$ & $57.5(9.7)$ & $52.2(10.1)$ & $<0.001$ \\
\hline $\begin{array}{l}\text { Ability to participate in social roles and } \\
\text { activities }\end{array}$ & $51.9(9.5)$ & $43.3(8.0)$ & $49.6(9.9)$ & $<0.001$ \\
\hline Satisfaction with social roles and activities & $48.7(9.0)$ & $4 I .2(6.9)$ & $46.7(9.1)$ & $<0.001$ \\
\hline Emotional support & $49.7(9.2)$ & $44.4(8.5)$ & $48.3(9.3)$ & $<0.001$ \\
\hline Informational support & $50.0(10.7)$ & $46.3(9.9)$ & $49.0(10.6)$ & $<0.001$ \\
\hline Social isolation & $48.0(9.4)$ & $56.8(9.3)$ & $50.3(10.1)$ & $<0.001$ \\
\hline Fatigue & $51.8(9.6)$ & $59.5(9.2)$ & $53.9(10.1)$ & $<0.001$ \\
\hline Sleep disturbance & $51.3(9.4)$ & $59.7(9.8)$ & $53.6(10.2)$ & $<0.001$ \\
\hline
\end{tabular}

Notes: Entries in the table represent the number of participants (percentage), or the mean (SD). ${ }^{\text {a }}$-value: chi-squared test, Fisher's exact test, or independent $t$-test for comparison of the caregiver groups, excluding missing data.

Abbreviations: GED, General Educational Development Test (High School Equivalency Diploma); HS, high school; MPAI-4, Mayo-Portland Adaptability Inventory-Fourth Edition; TBI, traumatic brain injury; SMV, service member/veteran; PROMIS, Patient-Reported Outcomes Measurement Information System.

comprised of all women, was younger, had fewer racial/ ethnic minorities, had more education, and nearly all were the spouse of a person with TBI (all $P<0.001)$. There was a higher proportion of low functioning SMVs compared to civilians $(51 \%$ vs $12 \% ; P<0.001)$. All HRQOL outcomes were poorer for the group caring for SMVs (all $P<0.001$ ). 
Table 2 summarizes information about the survey evaluation and response burden indicators. About half in each caregiver group reported that their study participation experience was about the same as expected, and about half reported that their experience was better than expected; only $6 \%$ in each group reported that their experience was worse than expected. The group caring for SMVs was more likely to report that they would recommend this study to others $(P=0.002)$, and they were more likely to have comments about their study participation $(P=0.006)$. Among those who had comments, about half in each group had negative comments. About half in each group rated the screen design as very good or excellent. The group caring for civilians needed more help to complete the questionnaires $(P=0.03)$ but took about the same length of time to complete them as the group caring for SMVs.

Caregivers were more likely to rate their study participation experience as a little/a lot better than expected if they had lower education or were racial/ethnic minorities (Table 3 ).
Caregiver group, MPAI-4 function, and HRQOL outcomes were not associated with study participation experience (all $P>0.10)$. The group caring for SMVs was more likely to report that they would recommend this study to others. Education, race/ethnicity, MPAI-4 function, and HRQOL outcomes were not associated with study recommendation (all $P>0.10$ ).

Participants with a more favorable overall rating of their study participation experience had a greater proportion of positive comments compared to those with less favorable ratings (Figure 1; $P<0.001$ ). Specifically, 56\% and 48\%, respectively, of those who rated their experience as a lot better or a little better than expected had positive comments compared to $4 \%$ and $27 \%$, respectively, for those who rated their experience as worse or about the same.

Those with less education and those from racial/ethnic minority groups needed more help using the computer or answering questions (Table 3). Caregiver group, MPAI-4 function, and HRQOL outcomes were not associated with the need for help (all $P>0.10$ ).

Table 2 Survey evaluation and response burden, by caregiver type

\begin{tabular}{|c|c|c|c|c|}
\hline & $\begin{array}{l}\text { Caregivers of } \\
\text { civilian TBI } \\
(n=335)\end{array}$ & $\begin{array}{l}\text { Caregivers of } \\
\text { SMV TBI } \\
(n=\mid 23)\end{array}$ & $\begin{array}{l}\text { Total } \\
(n=458)\end{array}$ & $P$-value ${ }^{a}$ \\
\hline \multicolumn{5}{|l|}{ Study participation experience } \\
\hline A lot worse/a little worse than expected & $21(6 \%)$ & $8(6 \%)$ & $29(6 \%)$ & 0.440 \\
\hline About the same as expected & 149 (44\%) & 61 (50\%) & $210(44 \%)$ & \\
\hline A little better than expected & $87(26 \%)$ & $23(19 \%)$ & $110(23 \%$ & \\
\hline A lot better than expected & $78(23 \%)$ & $31(25 \%)$ & $109(23 \%)$ & \\
\hline Would recommend this study to others & $27 \mid(81 \%)$ & $115(94 \%)$ & $386(84 \%)$ & 0.002 \\
\hline \multicolumn{5}{|l|}{ Comments about study participation } \\
\hline None & $164(49 \%)$ & 77 (63\%) & $24 \mid(53 \%)$ & 0.006 \\
\hline \multicolumn{5}{|l|}{ Type of comment } \\
\hline Positive & $59(35 \%)$ & $19(41 \%)$ & $78(36 \%)$ & 0.321 \\
\hline Negative & $82(48 \%)$ & $24(52 \%)$ & $106(49 \%)$ & \\
\hline Psychological & $20(12 \%)$ & $2(4 \%)$ & $22(10 \%)$ & \\
\hline Other & $10(6 \%)$ & $\mathrm{I}(2 \%)$ & II (5\%) & \\
\hline \multicolumn{5}{|l|}{ Overall rating of screen design } \\
\hline Poor/fair & $32(10 \%)$ & 14 (1 I\%) & $46(10 \%)$ & 0.890 \\
\hline Good & $122(36 \%)$ & $44(36 \%)$ & $166(36 \%)$ & \\
\hline Very good & $109(32 \%)$ & $43(35 \%)$ & $152(33 \%)$ & \\
\hline Excellent & $49(15 \%)$ & $22(18 \%)$ & $71(16 \%)$ & \\
\hline Missing & $23(7 \%)$ & 0 & $23(5 \%)$ & \\
\hline \multicolumn{5}{|c|}{ Help using the computer or answering the questions } \\
\hline Not at all & $266(79 \%)$ & 110 (89\%) & $376(82 \%)$ & 0.030 \\
\hline A little bit & $27(8 \%)$ & $4(3 \%)$ & $31(7 \%)$ & \\
\hline Some & $15(4 \%)$ & $6(5 \%)$ & $21(5 \%$ & \\
\hline A lot & $27(8 \%)$ & $3(2 \%)$ & $30(7 \%)$ & \\
\hline \multicolumn{5}{|l|}{ Time needed to complete the questionnaires } \\
\hline$\leq 3$ hours & $229(68 \%)$ & 89 (72\%) & $318(69 \%)$ & 0.466 \\
\hline Minutes to complete the questionnaires ${ }^{b}$ & $78(30)$ & $71(28)$ & $76(29)$ & 0.070 \\
\hline
\end{tabular}

Notes: Entries in the table represent the number of participants (percentage), or the mean (SD). ${ }^{\text {a }}$-value: chi-squared test, Fisher's exact test, or independent $t$-test for comparison of the caregiver groups, excluding missing data; bincluding only those who took 3 hours or less $(n=3 \mid 8)$.

Abbreviations: TBI, traumatic brain injury; SMV, service member/veteran. 
Table 3 Logistic regression models for evaluation/burden indicators

\begin{tabular}{|c|c|c|c|}
\hline \multirow[t]{2}{*}{ Dependent variable } & \multicolumn{3}{|c|}{ Independent variable } \\
\hline & SMV vs civilian & $\begin{array}{l}\text { More than HS } \\
\text { education vs less }\end{array}$ & $\begin{array}{l}\text { Non-Hispanic white } \\
\text { vs other }\end{array}$ \\
\hline Study participation experience: & - & $0.51(0.32,0.82)$ & $0.54(0.36,0.81)$ \\
\hline \multicolumn{4}{|l|}{ a little/a lot better than expected vs same/worse } \\
\hline Would recommend this study to others: yes/maybe vs no & $3.40(1.58,7.31)$ & - & - \\
\hline $\begin{array}{l}\text { Help using the computer or answering the questions: some/a } \\
\text { little/a lot vs not at all }\end{array}$ & - & $0.44(0.26,0.75)$ & $0.36(0.22,0.59)$ \\
\hline
\end{tabular}

Notes: Entries in the table represent the odds ratio $(95 \% \mathrm{Cl})$; all $P$-values $<0.05$.

Abbreviations: HS, high school; SMV, service member/veteran.

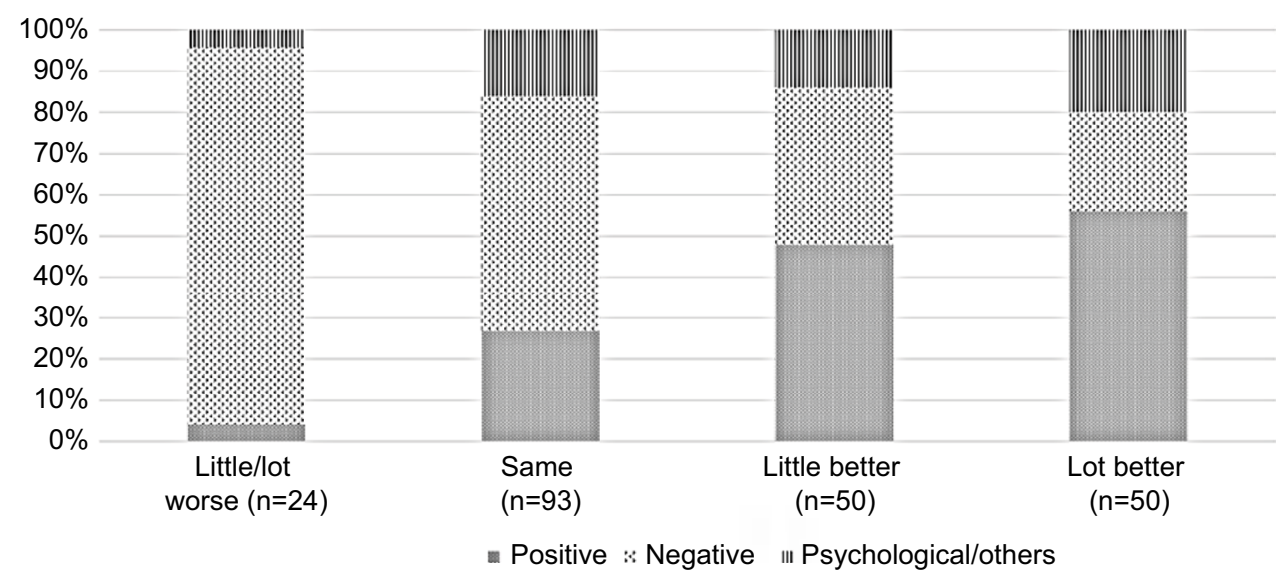

Figure I Association between rating of study participation experience and open-ended comments $(P<0.00 \mathrm{I})$.

\section{Discussion}

Participant ratings of survey response burden provide useful information for researchers and clinicians on the acceptability of a PRO instrument for a particular population and use. This is the first study to measure multiple indicators of PRO survey response burden in caregivers of civilians and SMVs with TBI. Overall, caregivers had generally favorable ratings of study participation experience, most would recommend the study to others, and most needed little help using the computer or answering the questions. Multivariable analyses of these burden indicators showed that caregivers with less education and those from racial/ethnic minority groups had more favorable ratings of their study participation experience, even though they needed more help using the computer or answering the questions. Receiving help with survey completion allowed them to participate successfully in the study. It is possible that some individuals may consider survey participation as a form of social support.

Although caregivers of SMVs in this study had poorer HRQOL outcomes compared to caregivers of civilians, they were more likely to report that they would recommend the study to others. HRQOL outcomes were not associated with study recommendations. It may be that these caregivers were simply more appreciative to be the focus of research efforts designed to better understand and ultimately improve their HRQOL. Anecdotally, many caregivers mentioned that they have few opportunities to participate in research. In addition, qualitative data suggest that caregivers of SMVs often do not feel like they have the opportunity to express their emotions, and in fact they feel the need to put on a brave face for others. ${ }^{5}$ Thus, it may also be possible that providing them with the opportunity and a relatively anonymous space to express their feelings might have been cathartic and may have led them to recommend this study to others.

There are some limitations to this study. Because convenience sampling was used, generalizability is limited with regard to racial/ethnic minorities, male caregivers, and caregivers who are parents or relations other than spouses. Caregivers of SMVs were primarily recruited through support organizations, and so results may not be representative of those who care for a person with a military-related TBI. It will be important to recruit caregivers through military medical centers in future studies. In addition, SMVs with TBI have high rates of other comorbid clinical conditions ${ }^{34}$ which could increase the caregiver burden. Comorbidities were not collected for this study, but would be important to 
incorporate in the design of future studies. The majority of the caregivers completed the survey at home; thus, it is possible that their survey evaluation was influenced by others.

PROs are widely gathered in clinical and health services research; they are increasingly collected and used in clinical practice settings as well. ${ }^{35-40}$ PROs are relevant for many activities: helping patients and their clinicians make informed decisions about health care, monitoring the progress of care, setting policies for coverage and reimbursement of health services, improving the quality of health care services, and tracking or reporting on the performance of health care delivery organizations. ${ }^{21}$ It might be useful to incorporate PROs into the TBI care programs developed by the Department of Defense and the Veterans Affairs Health Care Systems. ${ }^{41}$

The TBI-CareQOL measurement system offers unique measures of caregiver-specific HRQOL. The results of this study provide useful information about the acceptability of computer-based survey administration in caregivers of civilians and SMVs. Future work could consider adapting the TBI-CareQOL measurement system for caregivers of people with other conditions, eg, Alzheimer's disease. More data are needed to determine the best assessment strategies for individuals with lower education who are likely to require some assistance in completing PRO surveys. For example, studies evaluating PROs administered by multimedia platforms ${ }^{42-47}$ could help researchers and clinicians plan the best strategies for assessing HRQOL in TBI caregivers.

\section{Acknowledgment}

This work was supported by the National Institute of Nursing Research under Grant \#R01-NR013658.

\section{Disclosure}

The authors report no conflicts of interest in this work.

\section{References}

1. Verhaeghe S, Defloor T, Grypdonck M. Stress and coping among families of patients with traumatic brain injury: a review of the literature. J Clin Nurs. 2005;14(8):1004-1012.

2. Chronister J, Chan F, Sasson-Gelman EJ, Chiu CY. The association of stress-coping variables to quality of life among caregivers of individuals with traumatic brain injury. NeuroRehabilitation. 2010;27(1):49-62.

3. Kratz A, Carlozzi N, Brickell TA, Sander AM. "I Want ME as a Caregiver": perspectives from caregivers of individuals with traumatic brain injury. Arch Phys Med Rehabil. 2014;95(10):e50.

4. Carlozzi NE, Kratz AL, Sander AM, et al. Health-related quality of life in caregivers of individuals with traumatic brain injury: development of a conceptual model. Arch Phys Med Rehabil. 2015;96(1):105-113.

5. Carlozzi NE, Brickell TA, French LM, et al. Caring for our wounded warriors: a qualitative examination of health-related quality of life in caregivers of individuals with military-related traumatic brain injury. J Rehabil Res Dev. 2016;53(6):669-680.
6. Saban KL, Griffin JM, Urban A, Janusek MA, Pape TL, Collins E. Perceived health, caregiver burden, and quality of life in women partners providing care to Veterans with traumatic brain injury. J Rehabil Res Dev. 2016;53(6):681-692.

7. Griffin JM, Lee MK, Bangerter LR, et al. Burden and mental health among caregivers of veterans with traumatic brain injury/polytrauma. Am J Orthopsychiatry. 2017;87(2):139-148.

8. Taft CT, Schumm JA, Panuzio J, Proctor SP. An examination of family adjustment among Operation Desert Storm veterans. J Consult Clin Psychol. 2008;76(4):648-656.

9. Ruff RL, Ruff SS, Wang XF. Improving sleep: initial headache treatment in OIF/OEF veterans with blast-induced mild traumatic brain injury. J Rehabil Res Dev. 2009;46(9):1071.

10. Lester P, Peterson K, Reeves J, et al. The long war and parental combat deployment: effects on military children and at-home spouses. $J \mathrm{Am}$ Acad Child Adolesc Psychiatry. 2010;49(4):310-320.

11. Mansfield AJ, Kaufman JS, Marshall SW, Gaynes BN, Morrissey JP, Engel CC. Deployment and the use of mental health services among U.S. Army wives. N Engl J Med. 2010;362(2):101-109.

12. Phelan SM, Griffin JM, Hellerstedt WL, et al. Perceived stigma, strain, and mental health among caregivers of veterans with traumatic brain injury. Disabil Health J. 2011;4(3):177-184.

13. Carlozzi NE, Lange RT, French LM, Sander AM, Freedman J, Brickell TA. A latent content analysis of barriers and supports to healthcare: perspectives from caregivers of service members and veterans with military-related traumatic brain injury. J Head Trauma Rehabil. Epub 2018 Jan 30

14. Carlozzi NE, Kallen MA, Hanks R. The TBI-CareQOL measurement system: development and validation of health-related quality of life measures for caregivers of civilians and service members/veterans with traumatic brain injury. Arch Phys Med Rehabil. Epub 2018 Sep 06.

15. Cella D, Riley W, Stone A, et al. The Patient-Reported Outcomes Measurement Information System (PROMIS) developed and tested its first wave of adult self-reported health outcome item banks: 2005-2008. J Clin Epidemiol. 2010;63(11):1179-1194.

16. Bowling A. Mode of questionnaire administration can have serious effects on data quality. J Public Health. 2005;27(3):281-291.

17. Aaronson N, Alonso J, Burnam A, et al. Assessing health status and quality-of-life instruments: attributes and review criteria. Qual Life Res. 2002;11(3):193-205.

18. US Food and Drug Administration. Guidance for industry. Patientreported outcome measures: use in medical product development to support labeling claims; 2009. Available from: https://www.fda.gov/ downloads/drugs/guidances/ucm193282.pdf. Accessed October 03, 2018.

19. Groves RM. Survey Methodology. 2nd ed. Hoboken, NJ: John Wiley; 2009.

20. Dillman DA, Smyth JD, Christian LM. Internet, Mail, and Mixed-Mode Surveys: The Tailored Design Method. 4th ed. Hoboken, NJ: Wiley \& Sons; 2014.

21. Cella D, Hahn EA, Jensen SE. Patient-Reported Outcomes in Performance Measurement. In: Publication No. BK-0014-1509. Research Triangle Park, NC: RTI Press; 2015. Available from: https://www. ncbi.nlm.nih.gov/books/NBK424378/pdf/Bookshelf_NBK424378.pdf. Accessed August 22, 2018.

22. Dura JR, Kiecolt-Glaser JK. Sample bias in caregiving research. J Gerontol. 1990;45(5):P200-P204.

23. Weitzner MA, Jacobsen PB, Wagner H, Friedland J, Cox C. The Caregiver Quality of Life Index-Cancer (CQOLC) scale: development and validation of an instrument to measure quality of life of the family caregiver of patients with cancer. Qual Life Res. 1999;8(1-2):55-63.

24. Nabors N, Seacat J, Rosenthal M. Predictors of caregiver burden following traumatic brain injury. Brain Inj. 2002;16(12):1039-1050.

25. Williams CJ, Shuster JL, Clay OJ, Burgio KL. Interest in research participation among hospice patients, caregivers, and ambulatory senior citizens: practical barriers or ethical constraints? J Palliat Med. 2006;9(4):968-974. 
26. Deeken JF, Taylor KL, Mangan P, Yabroff KR, Ingham JM. Care for the caregivers: a review of self-report instruments developed to measure the burden, needs, and quality of life of informal caregivers. J Pain Symptom Manage. 2003;26(4):922-953.

27. Fayers PM, Machin D. Quality of Life: The Assessment, Analysis and Interpretation of Patient-Reported Outcomes. 2nd ed. Chichester, England: John Wiley \& Sons; 2007.

28. Rolstad S, Adler J, Rydén A. Response burden and questionnaire length: is shorter better? A review and meta-analysis. Value Health. 2011;14(8):1101-1108.

29. Blair J, Czaja RF, Blair EA. Designing Surveys: A Guide to Decisions and Procedures. 3rd ed. Thousand Oaks, CA: Sage Publications; 2014.

30. Hanauer DA, Mei Q, Law J, Khanna R, Zheng K. Supporting information retrieval from electronic health records: a report of University of Michigan's nine-year experience in developing and using the Electronic Medical Record Search Engine (EMERSE). J Biomed Inform. 2015;55:290-300.

31. Malec JF, Kragness M, Evans RW, Finlay KL, Kent A, Lezak MD. Further psychometric evaluation and revision of the Mayo-Portland Adaptability Inventory in a national sample. J Head Trauma Rehabil. 2003;18(6):479-492.

32. Malec J [webpage on the Internet]. The Mayo-Portland Adaptability Inventory: the center for outcome measurement in brain injury: 2005. Available from: http://www.tbims.org/combi/mpai. Accessed June 25, 2018.

33. DeWalt DA, Rothrock N, Yount S, Stone AA; PROMIS Cooperative Group. Evaluation of item candidates: the PROMIS qualitative item review. Med Care. 2007;45(5 Suppl 1):S12-S21.

34. Lange RT, Brickell TA, Kennedy JE, et al. Factors influencing postconcussion and posttraumatic stress symptom reporting following military-related concurrent polytrauma and traumatic brain injury. Arch Clin Neuropsychol. 2014;29(4):329-347.

35. Lohr KN, Zebrack BJ. Using patient-reported outcomes in clinical practice: challenges and opportunities. Qual Life Res. 2009;18(1):99-107.

36. Donaldson MS. Taking PROs and patient-centered care seriously: incremental and disruptive ideas for incorporating PROs in oncology practice. Qual Life Res. 2008;17(10):1323-1330.
37. Feldman-Stewart D, Brundage MD. A conceptual framework for patientprovider communication: a tool in the PRO research tool box. Qual Life Res. 2009;18(1):109-114.

38. Greenhalgh J. The applications of PROs in clinical practice: what are they, do they work, and why? Qual Life Res. 2009;18(1):115-123.

39. Rose M, Bezjak A. Logistics of collecting patient-reported outcomes (PROs) in clinical practice: an overview and practical examples. Qual Life Res. 2009;18(1):125-136.

40. Aaronson NK, Snyder C. Using patient-reported outcomes in clinical practice: proceedings of an International Society of Quality of Life Research conference. Qual Life Res. 2008;17(10):1295-1295.

41. The National Defense Authorization Act of 2007 (NDAA) [webpage on the Internet]. John Warner National Defense Authorization Act for Fiscal Year 2007, The National Defense Authorization Act of 2007 (NDAA), Section 744: TBI Family Caregiver Curriculum (FCC) [H.R. 5122]; 2007. Available from: https://www.govtrack.us/congress/bills/109/ hr5122/text. Accessed August 22, 2018.

42. Hahn EA, Cella D. Health outcomes assessment in vulnerable populations: measurement challenges and recommendations. Arch Phys Med Rehabil. 2003;84(4 Suppl 2):S35-S42.

43. Hahn EA, Cellal D, Dobrez DG, et al. Quality of life assessment for low literacy Latinos: a new multimedia program for self-administration. J Oncol Manag. 2003;12(5):9-12.

44. Hahn EA, Cella D, Dobrez D, et al. The talking touchscreen: a new approach to outcomes assessment in low literacy. Psychooncology. 2004;13(2):86-95.

45. Yost KJ, Webster K, Baker DW, Jacobs EA, Anderson A, Hahn EA. Acceptability of the talking touchscreen for health literacy assessment. $J$ Health Commun. 2010;15(Suppl 2):80-92.

46. Hahn EA, Choi SW, Griffith JW, Yost KJ, Baker DW. Health literacy assessment using talking touchscreen technology (Health LiTT): a new item response theory-based measure of health literacy. $J$ Health Commun. 2011;16(Suppl 3):150-162.

47. Hahn EA, Burns JL, Jacobs EA, et al. Health literacy and patientreported outcomes: a cross-sectional study of underserved English- and Spanish-speaking patients with type 2 diabetes. J Health Commun. 2015;20(Suppl 2):4-15.
Patient Related Outcome Measures

\section{Publish your work in this journal}

Patient Related Outcome Measures is an international, peer-reviewed, open access journal focusing on treatment outcomes specifically relevant to patients. All aspects of patient care are addressed within the journal and practitioners from all disciplines are invited to submit their work as well as healthcare researchers and patient support groups.

\section{Dovepress}

The journal is included in PubMed. The manuscript management system is completely online and includes a very quick and fair peer-review system. Visit http://www.dovepress.com/testimonials.php to read real quotes from published authors. 